\title{
Penggunaan Algoritma Vigenere Cipher dan RSA (Rivest-Shamir-Adleman) Untuk Keamanan Data Pembelian di PT Lamongan Marine Industry
}

\author{
Fifin Nur Aini ${ }^{1}$, Siti Amiroch ${ }^{2}$, Novita Eka Chandra ${ }^{3}$ \\ ${ }^{1}$ Universitas Islam Darul ‘ulum Lamongan, fifinna237@gmail.com \\ ${ }^{2}$ Universitas Islam Darul ‘ulum Lamongan, siti.amiroch@unisda.ac.id \\ ${ }^{3}$ Universitas Islam Darul ‘ulum Lamongan, novitaeka@ unisda.ac.id
}

\begin{abstract}
Purchasing data is very important for business actors because the data is very influential on companies, especially in the field of production and marketing. Therefore, the purchase data is one of the things that is kept secret by the business actors, such as PT Lamongan Marine Industry. With current technology hackers can easily hack such data, so the use of cryptography is a very appropriate solution to this problem. In this study the authors used the Vigenere Cipher algorithm and the RSA algorithm with a high security key. The hacker was not easy to find out the contents of the data. The data obtained is a purchase order, then presented in tabular form. The data is then encrypted and decrypted so that the comparison of the two algorithms is known. The results of the analysis state that the Vigenere Cipher algorithm is more effective in both encryption and decryption processing time. Ciphertext generated from the encryption process of the Vigenere Cipher algorithm is mostly in the form of punctuation, while the ciphertext generated by the RSA algorithm from the encryption process is mostly in alphabetical letters. The ciphertext generated by the RSA algorithm depends on the value of the modulo. but in terms of security the RSA algorithm is superior to the Vigenere Cipher algorithm.
\end{abstract}

Keywords: Vigenere Cipher, RSA, Purchase Data

\begin{abstract}
Abstrak. Data pembelian merupakan hal yang sangat penting bagi pelaku usaha karena data tersebut sangat berpengaruh pada perusahaan khususnya dalam bidang produksi dan pemasaran produk. Oleh karena itu data pembelian menjadi salah satu hal yang sangat dirahasiakan oleh sebuah intansi pelaku usaha, seperti PT Lamongan Marine Industry. Dengan teknologi saat ini peretas pun dapat meretas data tersebut dengan mudah, sehingga penggunaan kriptografi merupakan solusi yang sangat tepat untuk permasalahan tersebut. Dalam penelitian ini penulis menggunakan algoritma Vigenere Cipher dan algoritma RSA dengan kunci keamanan yang cukup tinggi peretas tidak mudah untuk mengetahui isi dari data tersebut. Data yang diperoleh adalah purchase order, kemudian disajikan dalam bentuk tabel. Data tersebut kemudian dienkripsi dan didekripsi agar diketahui perbandingan dari kedua algoritma tersebut. Hasil analisis menyatakan bahwa algoritma Vigenere Cipher lebih efektif dalam waktu proses enkripsi maupun dekripsi. Ciphertext yang dihasilkan dari proses enkripsi algoritma Vigenere Cipher lebih banyak berupa tanda baca, sedangkan ciphertext yang dihasilkan algoritma $R S A$ dari proses enkripsi lebih banyak berupa huruf abjad. Ciphertext yang dihasilkan algoritma RSA bergantung pada besarnya nilai modulo. Namun dalam hal keamanan algoritma RSA lebih unggul dari algoritma Vigenere Cipher.
\end{abstract}

Kata Kunci: Vigenere Cipher, RSA, Data Pembelian 


\section{Pendahuluan}

Keamanan data dan informasi merupakan hal sangat penting di era globalisasi saat ini. Pada umumnya, setiap institusi memiliki dokumen-dokumen penting dan bersifat rahasia yang hanya boleh dilihat oleh orang tertentu. Sistem informasi yang dikembangkan harus menjamin keamanan dan kerahasiaan dokumen-dokumen tersebut. Namun kendalanya bahwa media-media yang digunakan seringkali dapat disadap oleh pihak lain.

Kriptografi (cryptography) merupakan ilmu dan seni untuk menjaga pesan agar aman. "Crypto" berarti "secret" (rahasia) dan "graphy" berarti "writing" (tulisan). Para pelaku atau praktisi kriptografi disebut cyrptographers. Sebuah algoritma kriptografi (cryptographic algorithm) disebut cipher merupakan persamaan matematik yang digunakan untuk proses enkripsi dan dekripsi. Biasanya persamaan kedua matematik (untuk enkripsi dan dekripsi) tersebut memiliki hubungan matematis yang cukup erat [1].

Vigenere Cipher adalah suatu algoritma kriptografi klasik yang ditemukan oleh Giovan Battista Bellaso. Nama Vigenere sendiri diambil dari seorang yang bernama Blaise de Vigenere. Nama Vigenere diambil sebagai nama algoritma ini karena beliau menemukan kunci yang lebih kuat lagi untuk algoritma tersebut dengan metode autokey cipher meskipun algoritma dasarnya telah ditemukan lebih dahulu oleh Giovan Battista [2].

Algoritma RSA ditemukan pertama kali oleh Ron Rivest, Adi Shamir, dan Leonard Adleman pada tahun 1978. Nama RSA merupakan singkatan dari inisial nama mereka. Algoritma RSA merupakan algoritma kriptografi asimetris yang mempunyai dua kunci yaitu kunci publik dan kunci rahasia. Hingga saat ini algoritma $R S A$ merupakan salah satu algoritma yang paling maju dalam bidang kriptografi.

Algoritma Vigenere Cipher dan algoritma RSA merupakan dua algoritma yang sangat berbeda. Perbedaan dari kedua algoritma tersebut adalah kunci yang digunakan untuk proses enkripsi dan dekripsi. Untuk proses enkripsi dan dekripsi algoritma Vigenere Cipher menggunakan kunci yang sama, sedangkan untuk algoritma $R S A$ menggunakan kunci yang berbeda. Proses dan hasil penyandian yang dihasilkan dari kedua algoritma tersebut juga akan sangat berbeda, untuk itu dalam penelitian ini penulis akan membandingkan proses penyandian maupun pembentukan kunci dari kedua algoritma tersebut.

Penelitian sebelumnya terkait algoritma RSA dilakukan oleh [3], melakukan beberapa uji coba dengan kode hufman dan ASCII, disimpulkan bahwa kode huffman lebih cepat dalam proses penyandian dari pada kode ASCII.

Data pembelian merupakan hal yang sangat penting bagi pelaku usaha karena data tersebut sangat berpengaruh pada perusahaan khususnya dalam bidang produksi dan pemasaran produk. Oleh karena itu data pembelian menjadi salah satu hal yang sangat dirahasiakan oleh sebuah intansi pelaku usaha, seperti PT Lamongan Marine Industry. Dengan teknologi saat ini penyadap pun dapat menyadap data tersebut dengan mudah, sehingga penggunaan kriptografi merupakan solusi yang sangat tepat untuk permasalahan tersebut. Dengan menggunakan algoritma Vigenere Cipher dan algoritma RSA dengan kunci keamanan yang cukup tinggi penyadap tidak mudah untuk mengetahui apa isi dari data tersebut. Untuk itu dalam penelitian ini bertujuan untuk membandingkan 
algoritma Vigenere Cipher dan algoritma RSA dalam proses-proses penyandian maupun hasil yang diperoleh.

\section{Tinjauan Pustaka}

Pembelian adalah serangkaian tindakan untuk mendapatkan barang dan jasa melalui pertukaran dengan maksud untuk digunakan sendiri atau dijual Kembali [4]. Dokumen yang digunakan dalam proses pembelian diantaranya: surat permintaan pembelian, surat permintaan penawaran harga., surat order pembelian, laporan penerimaan barang, surat perubahan order pembelian, dan bukti kas keluar.

Kriptografi merupakan seni dan ilmu untuk memproteksi pengiriman data dengan mengubahnya menjadi kode tertentu dan hanya ditujukan untuk orang yang hanya memiliki sebuah kunci untuk mengubah kode itu kembali yang berfungsi dalam menjaga kerahasiaan data atau pesan [5].

Proses yang dilakukan untuk mengubah plaintext menjadi ciphertext disebut enkripsi (encryption) atau encipherment, sedangkan proses untuk mengubah ciphertext kembali ke plaintext disebut dekripsi (decryption) atau decipherment.

Vigenere cipher ditemukan oleh Giovan Battista Bellaso pada tahun 1553 dan dikembangkan oleh Blaisede Vigenere. Vigenere Cipher menggunakan bujur sangkar vigenere dan perhitungan [6] sebagai berikut:

Sedangkan rumus untuk dekripsi adalah:

$$
C_{i}=\left(P_{i}+K_{i}\right) \bmod 26,
$$

dengan

$$
P_{i}=\left(C_{i}-K_{i}\right) \bmod 26
$$

$C i=$ nilai desimal karakter ciphertext $\mathrm{ke}-\mathrm{i}$.

$P i=$ nilai desimal karakter plaintext ke-i.

$K i=$ nilai desimal karakter kunci ke-i.

\section{Metode}

Data yang digunakan dalam penelitian ini adalah data sekunder, yakni berupa data pembelian. Dari sekian banyak data pembelian penulis mengambil sampel data pembelian berupa Purchase Order. Data yang diperoleh penulis diperoleh dari Divisi Keuangan PT Lamongan Marine Industry pada tanggal 29 Juni 2018 Adapun langkah-langkah dalam melakukan penelitian ini sebagai berikut:

1. Peneliti mengambil data di Divisi Keuangan PT Lamongan Marine Industry.

2. Menyajikan data dalam bentuk tabel.

3. Membuat tabula recta dan tabel subtitusi.

4. Menentukan kata kunci yang dipakai dalam proses enkripsi pada algoritma Vigenere Cipher dan menentukan nilai dua bilangan prima yang akan digunakan untuk proses penyandian algoritma $R S A$.

5. Menyandikan data yang didapat dengan menggunakan Algoritma Vigenere Cipher dan Algoritma RSA dengan bantuan software Matlab.

6. Menganalisis hasil output yang didapat dari proses Penyandian 


\section{Hasil dan Pembahasan}

Hasil data pembelian yang disandikan dengan algoritma Vigenere Cipher dan algoritma RSA dengan menggunakan software Matlab dijelaskan pada tabel 1 dan tabel 2 berikut.

Tabel 1. Hasil Penyandian dengan Algoritma Vigenere Cipher

\begin{tabular}{|c|c|c|c|c|c|c|}
\hline No & $\begin{array}{c}\text { Nomor } \\
\text { PO }\end{array}$ & Supplier & Proyek & Nama Barang & $\begin{array}{l}\text { Jumlah } \\
\text { Barang }\end{array}$ & $\begin{array}{c}\text { Term } \\
\text { Payment }\end{array}$ \\
\hline 1 & $\begin{array}{l}\text { b33FF } \\
\text { EK4I4 } \\
\text { SeXF }\end{array}$ & $\begin{array}{l}\text { QhPZ4P } \\
\text { aGR'Pf }\end{array}$ & $\begin{array}{l}\text { bgR\4VhG } \\
\mathrm{RbV}\end{array}$ & $\begin{array}{l}\text { - bcZGc[3SR]]g\#^Ua^H } \\
\text { c4_hWZ } \\
\text { • ]b]]Y/UORbSXU1`_Z } \\
\text { \#_c=351hhcH1U }\end{array}$ & $\begin{array}{ll}\text { - } & \mathrm{GC} \# \mathrm{~S} \backslash \\
\text { - } & \mathrm{AC \# S} \backslash\end{array}$ & F3KRfX \\
\hline
\end{tabular}

Tabel 2. Hasil Penyandian dengan Algoritma RSA

\begin{tabular}{|c|c|c|c|c|c|c|}
\hline No & $\begin{array}{c}\text { Nomor } \\
\text { PO }\end{array}$ & Supplier & Proyek & Nama Barang & $\begin{array}{l}\text { Jumlah } \\
\text { Barang }\end{array}$ & $\begin{array}{c}\text { Term } \\
\text { Payment }\end{array}$ \\
\hline 1 & $\begin{array}{l}\text { X0:P681 } \\
\text { 8bMU5 }\end{array}$ & $\begin{array}{l}\text { BURIAN } \\
\text { bAQAX }\end{array}$ & $\begin{array}{l}\text { XYOFG } \\
\text { UbANG }\end{array}$ & $\begin{array}{ll}\text { - } & \text { Xp } \\
\text { ioqPainyRamfjmPuyi } \\
\text { h } \\
\text { - } \text { Nno } \\
\text { qjBqanjmQPGNOPY } \\
\text { TPJA }\end{array}$ & $\begin{array}{l}\text { - } 3+\mathrm{BH} \\
\text { - } 7+\mathrm{BH}\end{array}$ & 2Hami \\
\hline
\end{tabular}

Hasil analisis perbandingan dari algoritma vigenere cipher dan algoritma $R S A$ dijelaskan pada tabel 3 berikut.

Tabel 3. Analisis Perbandingan Algoritma Vigenere Cipher dan Algoritma RSA.

\begin{tabular}{|c|c|c|c|}
\hline No & Perbandingan & Algoritma Vigenere Cipher & Algoritma $R S A$ \\
\hline 1 & $\begin{array}{l}\text { Pembentukan } \\
\text { kunci }\end{array}$ & 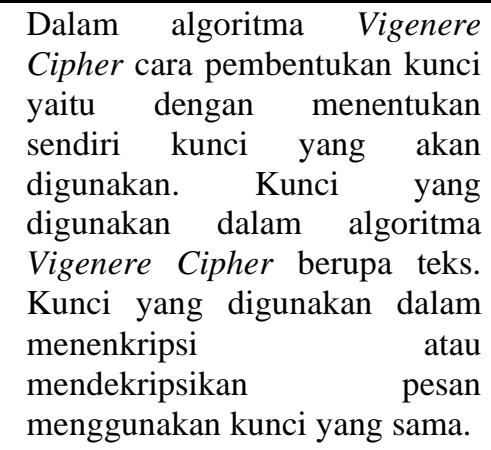 & $\begin{array}{l}\text { Dalam algoritma RSA proses } \\
\text { pembentukan kunci menggunakan } \\
\text { operasi perhitungan. Bilangan yang } \\
\text { digunakan dalam proses } \\
\text { perhitungan yaitu bilangan prima. } \\
\text { Dan hasil dari proses pembentukan } \\
\text { kunci algoritma } R S A \text { berupa public } \\
\text { key untuk menenkripsi pesan dan } \\
\text { private key untuk mendekripsi } \\
\text { pesan. }\end{array}$ \\
\hline 2 & Proses enkripsi & $\begin{array}{l}\text { Ada dua cara dalam proses } \\
\text { penyandian algoritma Vigenere } \\
\text { Cipher, yaitu: } \\
\text { a) Jika dalam proses penyandian } \\
\text { menggunakan tabula recta, } \\
\text { maka dalam proses } \\
\text { penyandian tidak ada operasi } \\
\text { perhitungan. }\end{array}$ & $\begin{array}{l}\text { Dalam proses penyandian algoritma } \\
R S A \text { menggunakan tabel subtitusi } \\
\text { maupun kode ASCII dengan rumus } \\
\text { yang sudah ditentukan sebelumnya. } \\
\text { Hasil enkripsi penyandian } \\
\text { algoritma } R S A \text { bergantung pada } \\
\text { besarnya nilai modulo pada kunci } \\
\text { yang dipakai. }\end{array}$ \\
\hline & & $\begin{array}{l}\text { b) Jika dalam proses penyandian } \\
\text { menggunakan tabel subtitusi } \\
\text { maupun kode ASCII maka } \\
\text { proses }\end{array}$ & $\begin{array}{l}\text { Waktu yang dibutuhkan dalam } \\
\text { proses dekripsi } 0,007 \text { detik. }\end{array}$ \\
\hline
\end{tabular}


menggunakan rumus dan operasi perhitungan.

Waktu yang dibutuhkan dalam proses enkripsi 0.002 detik

Ada dua cara dalam proses penyandian algoritma Vigenere Cipher, yaitu:

a) Jika dalam proses penyandian menggunakan tabula recta, maka dalam proses penyandian tidak ada operasi perhitungan.

b) Jika dalam proses penyandian menggunakan tabel subtitusi maupun kode ASCII maka proses penyandian menggunakan rumus dan operasi perhitungan.

c) Waktu yang dibutuhkan dalam proses enkripsi 0.002 detik

Proses dekripsi dalam algoritma Vigenere Cipher menggunakan kode ASCII dan rumus yang telah ditentukan, namun masih menggunakan kunci yang sama dengan proses enkripsi. Waktu yang digunakan proses dekripsi sama dengan proses enkripsi yaitu 0,002 detik.

Chipertext yang dihasilkan dari proses enkripsi dari algoritma Vigenere Cipher lebih banyak menghasilkan ciphertext berupa tanda baca daripada huruf abjad.
Dalam proses penyandian algoritma $R S A$ menggunakan tabel subtitusi maupun kode ASCII dengan rumus yang sudah ditentukan sebelumnya. Hasil enkripsi penyandian algoritma RSA bergantung pada besarnya nilai modulo pada kunci yang dipakai. Waktu yang dibutuhkan dalam proses dekripsi 0,007 detik.

Proses dekripsi dalam algoritma RSA menggunakan kode ASCII dan rumus yang telah ditentukan, namun menggunakan kunci yang berbeda (private key). Waktu yang digunakan proses dekripsi sama dengan proses enkripsi yaitu 0,005 detik.

Hasil enkripsi algoritma RSA berupa ciphertext diketahui tidak berbeda jauh dari karakter asli (plaintext), atau dapat dikatakan keluaran karakter pada cipherteks masih menghasilkan huruf abjad karena nilai modulo pada algoritma RSA mempengaruhi hasil keluaran karakter pada ciphertext Ada juga beberapa ciphertext yang sama dengan plaintextnya.

Selanjutnya dilakukan uji validasi yang bertujuan untuk mengetahui tingkat keamanan algoritma yang dipakai dalam penelitian ini. Berikut merupakan hasil perbandingan dua algoritma kriptografi yang telah di kriptanalis menggunakan dua metode untuk menguji keamanan algoritma yaitu metode kraitchik dan metode analisis frekuensi.

Input yang dibutuhkan dalam metode kraitchik untuk mengkriptanalis yaitu public key. Algoritma Vigenere Cipher merupakan algoritma kunci simetris, maka penggunaan metode kraitchik untuk mengkriptanalis algoritma kriptografi simetris tidak disarankan karena peretas dapat dengan mudah mengetahui plaintext yang dirahasiakan. Sedaangkan teknik pemecahan kunci dengan metode kraitchik berhasil diterapkan untuk mengkriptanalis kunci algoritma $R S A$. Waktu yang 
dibutuhkan bergantung pada besarnya bilangan prima yang dipakai dalam pembuatan kunci.

Pada metode analisis frekuensi input yang dibutuhkan dalam mengkriptanalis yaitu ciphertext dan menggunakan alat bantu tabel frekuensi. Langkah-langkah kriptanalis dengan metode analisis frekuensi sebagai berikut:

1. Analisis frekuensi pada algoritma Vigenere Cipher

a. Ambil Ciphertext $=$ QhPZ4PaGR`Pf

b. Hitung frekuensi kemunculan relatif huruf-huruf di dalam ciphertext.

Tabel 4. Perhitungan Frekuensi Kemunculan Huruf dalam Ciphertext

\begin{tabular}{ccc}
\hline Karakter & Jumlah & Frekuensi Kemunculan \\
\hline $\mathrm{Q}$ & 1 & $8,33 \%$ \\
$\mathrm{~h}$ & 1 & $8,33 \%$ \\
$\mathrm{P}$ & 3 & $25 \%$ \\
$\mathrm{Z}$ & 1 & $8,33 \%$ \\
4 & 1 & $8,33 \%$ \\
$\mathrm{a}$ & 1 & $8,33 \%$ \\
$\mathrm{G}$ & 1 & $8,33 \%$ \\
$\mathrm{R}$ & 1 & $8,33 \%$ \\
- & 1 & $8,33 \%$ \\
$\mathrm{f}$ & 1 & $8,33 \%$ \\
\hline Jumlah & 12 & $100 \%$ \\
\hline
\end{tabular}

Dari Tabel 4 dapat diketahui bahwa karakter $\mathrm{P}$ merupakan karakter yang sering muncul dalam ciphertext. Kemungkinan $\mathrm{P}$ merupakan pemetaan dari a, namun hasil pemetaan tersebut belum dapat dipastikan kebenarannya karena diperlukan trial and error dan pengetahuan tentang bahasa yang dipakai.

Iterasi 1

$$
\begin{array}{llllllllllll}
\mathbf{Q} & \mathbf{h} & \mathbf{P} & \mathbf{Z} & \mathbf{4} & \mathbf{P} & \mathbf{a} & \mathbf{G} & \mathbf{R} & \cdots & \mathbf{P} & \mathbf{f} \\
\mathrm{a} & & & \mathrm{a} & & & & & \mathrm{a} &
\end{array}
$$

Karena karakter yang lain mempunyai frekuensi yang sama, maka pemetaan dilakukan dengan mencari karakter pada Tabel Frekuensi yang mempunyai nilai yang berdekatan satu sama lain. dengan memperhatikan nilai frekuensi dalam Tabel 4.

Iterasi 2

$$
\begin{array}{llllllllllll}
\mathbf{Q} & \mathbf{h} & \mathbf{P} & \mathbf{Z} & \mathbf{4} & \mathbf{P} & \mathbf{a} & \mathbf{G} & \mathbf{R} & \ddots & \mathbf{P} & \mathbf{f} \\
2 & 5 & \mathrm{a} & \mathrm{B} & \mathrm{I} & \mathrm{a} & \mathrm{L} & \mathrm{M} & \mathrm{N} & \mathrm{S} & \mathrm{a} & \mathrm{D}
\end{array}
$$

Langkah ini dilakukan sampai semua karakter yang mempunyai nilai frekuensi yang berdekatan telah diacak hingga membentuk sebuah kata atau kalimat.

Iterasi 15

$$
\begin{array}{llllllllllll}
\mathbf{Q} & \mathbf{h} & \mathbf{P} & \mathbf{Z} & \mathbf{4} & \mathbf{P} & \mathbf{a} & \mathbf{G} & \mathbf{R} & \ddots & \mathbf{P} & \mathbf{f} \\
\mathrm{B} & \mathrm{U} & \mathrm{M} & \mathrm{I} & \mathrm{e} & \mathrm{a} & \mathrm{N} & \mathrm{D} & \mathrm{a} & \mathrm{L} & \mathrm{a} & \mathrm{S}
\end{array}
$$

Dari hasil iterasi karakter e dalam iterasi 15 kemungkinan merupakan spasi dan dapat disimpulkan bahwa plaintext yang dihasilkan yaitu BUMI ANDALAS. 
2. Analisis frekuensi pada algoritma $R S A$

a. Ambil Ciphertext $=$ BURIANbAQAX

b. Hitung frekuensi kemunculan relatif huruf-huruf di dalam ciphertext.

Tabel 5. Perhitungan Frekuensi Kemunculan Huruf dalam Ciphertext

\begin{tabular}{ccc}
\hline Karakter & Jumlah & Frekuensi Kemunculan \\
\hline B & 1 & $9,09 \%$ \\
U & 1 & $9,09 \%$ \\
R & 1 & $9,09 \%$ \\
I & 1 & $9,09 \%$ \\
A & 3 & $27,27 \%$ \\
N & 1 & $9,09 \%$ \\
b & 1 & $9,09 \%$ \\
Q & 1 & $9,09 \%$ \\
X & 1 & $9,09 \%$ \\
\hline Jumlah & 11 & $100 \%$ \\
\hline
\end{tabular}

Dari Tabel 5 dapat diketahui bahwa karakter P merupakan karakter yang sering muncul dalam ciphertext. Kemungkinan A merupakan pemetaan dari a, namun hasil pemetaan tersebut belum dapat dipastikan kebenarannya karena diperlukan trial and error dan pengetahuan tentang bahasa yang dipakai.

Iterasi 1

$$
\begin{array}{lllllllllll}
\mathbf{B} & \mathbf{U} & \mathbf{R} & \mathbf{I} & \mathbf{A} & \mathbf{N} & \mathbf{b} & \mathbf{A} & \mathbf{Q} & \mathbf{A} & \mathbf{X}
\end{array}
$$

Karena karakter yang lain mempunyai frekuensi yang sama, maka pemetaan dilakukan dengan mencari karakter pada Tabel Frekuensi yang mempunyai nilai yang berdekatan satu sama lain. dengan memperhatikan nilai frekuensi dalam Tabel 5.

Iterasi 2

$$
\begin{array}{cccccccccccc}
\mathbf{B} & \mathbf{U} & \mathbf{R} & \mathbf{I} & \mathbf{A} & \mathbf{N} & \mathbf{b} & \mathbf{A} & \mathbf{Q} & \mathbf{A} & \mathbf{X} & \mathbf{B} \\
" & - & . & 3 & \mathrm{a} & 8 & \mathrm{D} & \mathrm{a} & \mathrm{E} & \mathrm{a} & \mathrm{G} & \mathrm{P}
\end{array}
$$

Langkah ini dilakukan sampai semua karakter yang mempunyai nilai frekuensi yang berdekatan telah diacak hingga membentuk sebuah kata atau kalimat Iterasi 34

$$
\begin{array}{llllllllllll}
\mathbf{B} & \mathbf{U} & \mathbf{R} & \mathbf{I} & \mathbf{A} & \mathbf{N} & \mathbf{b} & \mathbf{A} & \mathbf{Q} & \mathbf{A} & \mathbf{X} & \mathbf{B} \\
\mathrm{G} & \mathrm{E} & \mathrm{m} & \mathrm{P} & \mathrm{a} & 3 & 8 & \mathrm{~m} & \mathrm{u} & \mathrm{a} & \mathrm{r} & \mathrm{a}
\end{array}
$$

Dari hasil iterasi 34 dapat disimpulkan bahwa plaintext yang dihasilkan yaitu gempa38muara

\section{Kesimpulan}

Dari pembahasan diatas dapat disimpulkan bahwa dalam proses pembentukan kunci algoritma $R S A$ lebih rumit jika dibandingkan dengan algoritma Vigenere Cipher karena algoritma RSA dalam pembentukan kunci 
melalui operasi perhitungan, sedangkan untuk algoritma Vigenere Cipher pembentukan kuncinya tidak melalui proses perhitungan. Proses enkripsi dan dekripsi algoritma Vigenere Cipher menggunakan kunci sama, sedangkan algoritma RSA menggunakan kunci yang berbeda (public key dan private key). Dalam proses penyandian algoritma Vigenere Cipher dapat menggunakan dua cara, yaitu dengan rumus yang ditentukan dan dengan tabula recta. Rumus yang digunakan dalam algoritma Vigenere Cipher sangat sederhana dan perhitungannya tidak menggunakan nilai yang cukup besar seperti algoritma RSA. Waktu yang dibutuhkan algoritma Vigenere Cipher dalam proses enkripsi relatif lebih cepat dari algoritma RSA. Jumlah karakter plaintext yang akan dienkripsi juga mempengaruhi waktu yang dibutuhkan. Hasil yang didapat dari penyandian algoritma Vigenere Cipher lebih banyak menghasilkan ciphertext berupa tanda baca berbeda dengan algoritma $R S A$ yang lebih banyak menghasilkan ciphertext berupa huruf abjad, karena bergantung pada besarnya nilai modulo pada kunci yang dipakai.

\section{Daftar Pustaka}

[1] J. Sasongko, "Pengamanan Data Informasi menggunakan Kriptografi Klasik," Dinamik, vol. 10, no. 3, 2005.

[2] A. Pudoli, A. Muchbarak, and S. H. Farham Harvianto, "Keamanan Data Pada File Excel Dengan Menggunakan Vigenere Cipher.” Mei, 2014.

[3] S. A. Fauji, M. S. Pradana, and N. A. Azhari, "Penerapan Kode Huffman Pada Algoritma RSA (Rivest-Shamir-Adleman) Untuk Menyandikan Password Email," Unisda J. Math. Comput. Sci., vol. 2, no. 1, pp. 41-49, 2016.

[4] D. N. Permata, L. Lambey, and S. Tangkuman, "Analisis Penerapan Sistem Informasi Akuntansi Pembelian Suku Cadang Pada Pt. Hasjrat Abadi Sudirman Manado," Going Concern J. Ris. Akunt., vol. 12, no. 2, 2017.

[5] F. N. Pabokory, I. F. Astuti, and A. H. Kridalaksana, "Implementasi Kriptografi Pengamanan Data Pada Pesan Teks, Isi File Dokumen, Dan File Dokumen Menggunakan Algoritma Advanced Encryption Standard," Inform. Mulawarman J. Ilm. Ilmu Komput., vol. 10, no. 1, pp. 20-31, 2016.

[6] T. Cahyadi, "Implementasi steganografi LSB dengan enkripsi vigenere cipher pada citra JPEG," Transient J. Ilm. Tek. Elektro, vol. 1, no. 4, pp. 281-288, 2012. 